Connecticut College

Digital Commons @ Connecticut College

6-18-2016

\title{
Ageing and Long-Term Care Planning Perceptions of Hispanics in the USA: Evidence from a Case Study in New London, Connecticut
}

María Amparo Cruz-Saco

Mónika López-Anuarbe

Follow this and additional works at: https://digitalcommons.conncoll.edu/econfacpub

Part of the Health Economics Commons, and the Latina/o Studies Commons

This Article is brought to you for free and open access by the Economics Department at Digital Commons @ Connecticut College. It has been accepted for inclusion in Economics Faculty Publications by an authorized administrator of Digital Commons @ Connecticut College. For more information, please contact bpancier@conncoll.edu.

The views expressed in this paper are solely those of the author. 


\title{
Ageing and Long-Term Care Planning Perceptions of Hispanics in the USA: Evidence from a Case Study in New London, Connecticut
}

\begin{abstract}
This paper explores the ageing attitudes and long-term care planning behavior of adult Hispanics in New London, Connecticut, a town with 30 thousand inhabitants that is rapidly ageing. We conducted six focus groups and had 37 participants share their ageing perceptions and long-term care needs. Our main findings suggest that informal care arrangements are vulnerable and unsustainable especially since women have historically and disproportionately provided most family eldercare even at their own personal and financial expense. Though male participants expected their female relatives to care for them when they age and need personal assistance, female participants did not necessarily expect the same from their relatives including their daughters. Also, both formal and government long-term care systems lack cultural competence and can be prohibitively costly. Therefore, Hispanics plan for ageing within their circles of family care and their resilience in a context of cultural exclusion and socio-economic disadvantage epitomizes strong intergenerational values. These support networks may help explain why may outlive whites (the "Hispanic paradox") who, on average, have higher wealth and education levels. Long-term care planning is a complex process that cannot be relayed to families only. Adequate training for family members from other relatives, and from private and government entities to appropriately convey this type of planning is vital to ensure that Hispanic families understand their options.
\end{abstract}

\section{Keywords}

Ageing and filial care, Long-term care planning, Economics of ageing, Economics of kin, Latino studies, Gender and women studies, Intergenerational solidarity, Intergenerational transfers

\author{
Disciplines \\ Economics | Health Economics | Latina/o Studies
}

\section{Comments}

This is an authors' postprint. Original version published online: 18 June 2016, Ageing Int (2017) 42:488-503

DOI 10.1007/s12126-016-9249-3

(C) Springer Science+Business Media New York 2016 


\begin{abstract}
This paper explores the ageing attitudes and long-term care planning behavior of adult Hispanics in New London, Connecticut, a town with 30 thousand inhabitants that is rapidly ageing. We conducted six focus groups and had 37 participants share their ageing perceptions and long-term care needs. Our main findings suggest that informal care arrangements are vulnerable and unsustainable especially since women have historically and disproportionately provided most family eldercare even at their own personal and financial expense. Though male participants expected their female relatives to care for them when they age and need personal assistance, female participants did not necessarily expect the same from their relatives including their daughters. Also, both formal and government long-term care systems lack cultural competence and can be prohibitively costly. Therefore, Hispanics plan for ageing within their circles of family care and their resilience in a context of cultural exclusion and socioeconomic disadvantage epitomizes strong intergenerational values. These support networks may help explain why may outlive whites (the "Hispanic paradox") who, on average, have higher wealth and education levels. Long-term care planning is a complex process that cannot be relayed to families only. Adequate training for family members from other relatives, and from private and government entities to appropriately convey this type of planning is vital to ensure that Hispanic families understand their options.
\end{abstract}




\section{Keywords}

Ageing and filial care, long-term care planning, economics of ageing, economics of kin,

Latino studies, gender and women studies, intergenerational solidarity, intergenerational transfers. 


\section{Introduction}

New London, Connecticut is a small coastal city in the United States (U.S.) home to a diverse population of thirty thousand. One third of its population is Hispanic, and this proportion is projected to grow (U.S. Census 2010). Economic activity is largely based on services including commerce, tourism, communication, and high-skill services provided by a large pharmaceutical global research center, the local hospital, one community health center, other health care providers, three colleges, and a variety of consulting firms. Most Hispanic residents are in the labor force but some have lowerthan-average formal education and English language or skill levels, higher uninsurance rates, and a higher poverty incidence when compared to the overall population (U.S. Census 2010).

In this context, we sought to better understand how Hispanic families and older persons interpret their own ageing and how they plan for their long-term care. Our three main research questions were:

1. How do our Hispanic participants conceptualize the meaning of ageing?

2. How do our Hispanic participants plan for old age?

3. How do personal characteristics and circumstances such as age, gender, education level, cultural background, and family values affect ageing attitudes? 
Over the spring of 2012, we conducted six focus groups to understand Hispanic caregiving perceptions and gather information to answer our research questions. The lively discussions and thoughtful exchanges provided rich evidence about ageing notions and planning attitudes. Findings show that our participating Hispanics construed ageing in conjunction with their active family engagement. For individuals 65 and older, a person remains "young" if he or she remains "of use." Likewise, a high degree of intergenerational solidarity (bonding, social and financial ties among generations) and coresidence with older relatives go hand in hand with strong bonds among these Hispanic family members who expressed that feelings of belonging and caring for older persons are part of the culture for all education levels, with women playing an important role as caregivers nevertheless.

\section{Literature review}

The literature on social constructs of ageing and planning among Hispanics is relatively scant, perhaps because most Hispanics ageing in the U.S. are first and second generations. In addition, the term "Hispanic" is relatively recent, controversial and complex. It wasn't used in the United States until the Census classified people from Latin America and some Caribbean nations as such in 1970 (Pew Research Center, 2010). This term includes a heterogeneous population representing over twenty national backgrounds, with first, second, or higher order generation migrants, and multiple ethnicities from the same country. Hence, cross-cultural and cross-disciplinary research on ageing attitudes remains a novel field that requires methodological syncretism and an epistemological 
domain beyond established disciplinary boundaries. Nevertheless, a review of the relevant literature reveals the existence of a few important themes:

- Hispanics in the U.S. are ageing rapidly and thereby transforming the demographic composition of people over 65 .

- Intergenerational solidarity and bonding among Hispanics help support older persons.

- Hispanics face socioeconomic challenges that may lead to a greater vulnerability in the support of older persons.

Older persons in the U.S. are becoming more racially and ethnically diverse (U.S. Census Bureau 2010). This reality calls for more adequate health care and long-term care policies and programs acknowledging cultural, racial, and ethnic differences. Hispanics will represent 22.5 per cent of the total population over 65 by 2030, and this percentage will continuously grow (U.S. Census 2010). Connecticut's high fertility and modest mortality rates, coupled with an increasing number of adult Hispanic migrants arriving annually, will most likely cause the highest growth rates from the youngest and from the oldest, too. This demographic issue will result in exceptionally high dependency ratios (Treas and Batalova 2007). In fact, by 2030 the Hispanic dependency ratio in Connecticut will jump from 67 (number of those under 18 and over 65 per 100 in the labor force) to 82 (Rodriguez, 2008); most of this increase will be tied to the rise of older Hispanics. As a 
result, adult Hispanics will increasingly feel the financial, physical, and emotional stress of caregiving for their ageing parents and relatives.

Intergenerational solidarity in traditional societies can be harmonious and mutually accommodating (Lowenstein 2000, 2005, 2007, 2010; Bengtson and Mangen 1988; Bengtson et al. 2000; Bengtson et al. 2002; Bengtson et al. 2003). However, it may also be complex, conflicted, and ambivalent when generations differ in the way they assimilate family roles or when these roles and attitudes change from generation to generation (Bengtson and Oyama 2010). This juxtaposition seems to reflect the situation among some Hispanics who juggle family caregiving responsibilities (including eldercare) with socio-economic disadvantages when they earn lower incomes and live in less affluent neighborhoods.

Cultural constructs of the elderly emphasize respect for their wisdom and experience thus granting them a privileged position in the family (Hilton et al. 2012; Beyene et al. 2002; Bermúdez et al. 2010; Radina and Barber 2004). Multiple interrelated social networks of care place the filial obligations of children to their parents at the core of family networks. Burr and Mutchler (1999) found that, relative to whites, Hispanics and Asians felt more often that parents should co-reside with adult children in multigenerational households. In addition, the cultural privilege attributed to masculinity has meant that the role of adult children in the care of their parents is highly gendered (Angel et al. 1997) falling heavily on the shoulders of women (Brewer 2001). In contrast, some communities that adhere to 
individualism place older persons in a subordinate position since they are seen as less capable of caring for themselves and are pushed aside to allow for younger, more productive members to lead (Foner 2009).

Bonding among Hispanics expands the reach of social networks beyond parents, children, and siblings to other family members, friends, neighbors, religious leaders, and members of the local community (Ruiz and Ransford 2012). The power of these social networks has been identified as a reason for the "barrio effect" (the neighborhood effect), where elderly Hispanics living in areas surrounded by co-ethnics experience better physical and mental well-being due to the availability of cultural and social support (Aranda et al. 2011). In cases when older parents and relatives live abroad, Hispanics sent money back home to continue supporting them. The emerging transnational care networks across multiple generations is receiving increasing scholarly attention (Menjivar and Abrego 2009; Dreby 2009; Foner 2009; Gilbertson 2009). Transnational arrangements, however, are difficult to manage from far away. They produce considerable strain for adult children and undue hardship for aged parents. Gilbertson 2009 shows that older parents are shuttled across borders as siblings try to accommodate each other's family and work commitments.

Older Hispanics tend to do better than white older persons because their well-being is sustained by the vitality of a community, in the sense of being useful or active, and by the comfort of being immersed in a network where there is cultural familiarity and support. 
But elderly parents living with adult children could have a negative experience if parents feel that they lack autonomy or that they do not contribute to the family's well-being (Angel et al. 1999; Treas and Carreon 2010). In the last few decades, Hispanics in the U.S. have outlived non-Hispanic whites despite their lower incomes and lower educational levels (Scommegna, 2013). This outcome is referred to as the so-called "Hispanic paradox." Reasons that may explain such a paradox include healthier nutrition habits and tighter family support networks that increase a sense of wellbeing and happiness. Thus, the power of informal support networks in Hispanic communities buffers ageing persons against the morbidity and mortality expected to result from a lifetime of struggle (Aranda et al. 2011; Kirby and Lau 2010).

In addition to the potential nuisance and uncertainty associated with increasingly complex systems of social ties for Hispanics living in the U.S., the network's effectiveness to provide informal care is also influenced by resource availability. This situation becomes problematic when the ageing parent is frail and requires extended care. While this socioeconomic disadvantage certainly varies across Hispanic sub-groups, such as Puerto Ricans, this vulnerability has lasted for decades (Baker 2002). Thus, a cultural system that heavily relies on informal care networks will be hard-pressed to function well if resources are not available. Older persons may artificially extend the boundaries of who is family to compensate for this situation (Ruiz and Ranford 2012). They are also more reliant on entitlement programs such as Social Security (Gassoumis et al. 2010) and Medicaid. Hispanics who need long-term care and are institutionalized will end up in 
substandard facilities that lack the resources to meet their needs, may be treated poorly (Feng et al. 2011; Fennell et al. 2010), and in culturally insensitive ways (Ryvicker 2011, Angel et al. 2004).

Given the likelihood that economic circumstances will result in the family's inability to care for their older relatives, cultural protocols have subtly changed the ways in which Hispanics define care obligations in the face of economic vulnerability. For example, there has been a shift away from the obligation of adult children caring for their parents to the obligation of ageing parents to not be a burden to their children (Heyman and Gutheil 2010). Recent scholarship has found that the direction of dependence is shifting downwards as more Hispanic adult children are dependent on ageing parents (Treas 2009). Ageing parents may financially provide for their adult children, cook meals, do housework and home maintenance, and be a key childcare source for grandchildren (Treas and Mazumdar 2002, Bengston and Oyama 2010).

While many Hispanics may prefer and expect family members to be involved in supporting the well-being of older parents and relatives (Blackhall et al. 1995), communication across generations on this difficult subject can be problematic. Ageing parents and relatives seem to resist such conversations because they want to protect their children from the burden of their care (Carr 2011). At the same time, adult children may worry that such conversations would make their parents anxious by "tempting fate" (Gutheil and Heyman 2006). Resistance to address end of life, fatalism, and a strong 
belief that God and prayer will provide for the well being in later life can deter difficult conversations between generations such as will and testament preparations (Edgell and Docka 2007; Herrera et al. 2009; Tait et al. 2011, Heyman and Gutheil 2010). As a result, research shows that, compared to other ethnic and cultural groups, Hispanics are the least informed about long-term health care issues and end-of-life planning (Caralis et al.1993; Delgadillo et al. 2004). One problem that has been documented in the scholarship is both lack of access and availability of information, especially in Spanish (Delgadillo et al. 2004).

\section{Methodology}

Our research was approved by the Connecticut College Institutional Research Board in February, 2012, and funded by a small grant from the Margaret Sheridan Research Fund and a Connecticut College Research Matters grant. Preparation and implementation of the qualitative research were carried out by a team of three Hispanic and bilingual researchers (two economists and one sociologist) and five students during the spring of 2012. Students were either fluent or highly proficient in Spanish. We used focus groups because this instrument helps identify key issues when the subject matter is not excessively sensitive and when time needs to be used efficiently and within a small budget (Warren and Karner 2009). This method is becoming increasingly popular and effective in studies of ageing and planning (Koenig 2004; Kelley et al. 2010; Borrayo et al. 2007; Ragin and Amoroso 2011). 
Our six focus groups were conducted over a three-month period with a total of 37 participants. The number of participants in each focus group ranged from five to eight, which is in line with what Debus (1988) and Warren and Karner (2009) note as an ideal size. All participants signed a confidentiality agreement, answered a brief questionnaire prior to participating in the session, and obtained a debriefing statement. The focus groups were conducted in Spanish at the request of participants. We designed the groups according to the variables that we wanted to control (Mijoba 2012). To assess potential family caregiving dynamics, we included family members in two of our focus groups. And we designed two focus groups staffed with only females to better understand gender roles and the presumed disproportionate caregiving responsibilities of women. Finally, to assess viewpoints that could vary according to education level, we designed one focus group with career-oriented and college educated participants, and another focus group with participants who had some high school education or completed high school diplomas.

Participants were aged 35 and above and were recruited with assistance of our community partners the Hispanic Alliance, the Community Health Center and the Provenance Center. The Hispanic Alliance is a nonprofit organization that administers several programs for Hispanics (healthcare, education, leadership development, and emergency funds). The Community Health Center is the second largest health facility in New London providing health care services to more than 7,000 Hispanic patients. The Provenance Center promotes cultural awareness through its educational and artistic 
programs. We also recruited participants at cultural centers, educational institutions, supermarkets, Latino restaurants, beauty shops, and travel agencies that serve the Hispanic community. We explained the purpose of the project to potential recruits and solicited their participation in one of our focus groups. To ensure a diverse sample in terms of educational and socio-economic level, we also recruited employees performing different types of jobs at organizations such as Connecticut College, Pfizer, the New London public school system, Lawrence Memorial Hospital, and the Community Health Center.

92 percent of our participants spoke Spanish as their primary language; 84 percent were born outside the U.S.: one-third Puerto Ricans, one-third Peruvians, one-tenth Dominicans and Colombians, and smaller numbers Panamanians, Venezuelans, and Salvadorians. This representation roughly covers the different foreign nationalities in New London. 94 percent defined themselves as Hispanic and six percent as white Hispanic. The large majority, 82 percent, had children; two-thirds were employed; and over two-thirds provided care for an older person at home. 42 percent were married, onefifth was divorced, 18 percent were single, and 15 percent were either separated or widowed. One-third was aged 35 to 44, fifty percent were aged 45 to 64 years, and 18 percent were older than 65 . One-third had high school education only, 28 percent had some college education, and another third had at least a college or professional degree. 
As we proceeded with recruiting participants, we aimed to approximate the characteristics of the local Hispanic population, but that proved to be somewhat difficult: three-quarters of participants were female. Their disproportionate number may reflect their greater interest in the topic and availability to participate. Hispanic females are more likely to be the primary caretakers and to live longer; but as elderly, they are also at high risk of living in poverty given their lifetimes of lower income and fewer assets (Angel et al. 2003). Given the significant issues that directly confront Hispanic females, we were comfortable with their over-representation in our sample.

\section{Questions and instrumentation}

We used a non-directive moderating approach with two open-ended and non-biasing questions: "What does ageing mean to you?" and "Did you/are you planning for your senior years?" We also prepared a series of prompt questions to ensure that the conversations would address the issues we were exploring. Examples of these questions included: "What do you feel are the changes implied by ageing?" "Do you feel that they vary by gender?" "How do you prepare for ageing?" "Do you have expectations about residing with your children?" We repeated questions as needed, provided clarifications and examples, actively listened, and presented brief summaries of what we heard to guarantee that we were in agreement regarding each person's contribution.

In preparation, we ran a pilot focus group to ensure that the participants' voices would flow and to allow themes to organically emerge. Keeping the questions to a minimum 
and using prompts facilitated a rich exchange; responses were affected by the social dynamics of the group (Hollander 2004). One response or comment would trigger a series of exchanges that took us in unanticipated directions, thereby enhancing the richness, depth, and number of emerging themes.

We chose to manually transcribe conversations verbatim due to the uneasiness with audio recording revealed in our pilot. This feeling often arises among individuals who feel excluded from mainstream society (Liamputtong, 2011). To ensure complete transcripts, each researcher took on a different role: one served as primary facilitator, two researchers typed the conversations, and a fourth researcher recorded non-verbal expressions and communication. The primary facilitator wrote down main ideas on poster board sheets and the other two typists transcribed in real time on their laptops. We compared both typed transcripts and they overlapped. When needed, we stopped the conversation and alerted participants that typists needed to catch up or requested clarification. This process made the conversation more engaging. Within one to two days of the session (at which time, transcripts were completed), we met as a group to debrief the session and glean emerging themes. Our poster board sheets also served as additional note taking sources.

\section{Analysis}

We used NVivo qualitative data analysis software to organize, analyze, and examine relationships in the verbatim transcripts. After summarizing and identifying issues and trends, we reduced the material through coding of signs and symbols as the first step in 
content analysis. It generated a list of recurrent variables and issues reflecting the attitudes, perceptions, and expectations of participants. We then moved to the explication and clarification of said variables and issues. Finally, we proceeded to structure the explanation of attitudes and ageing behavior. Given the richness of information that was summarized and coded, we obtained plenty of evidence to answer our research questions.

\section{Findings}

Our main findings are the following: Participants from different ages and education levels expressed values of Hispanic traditional societies. Both long-term care planning and caregiving expectations were also vastly gendered. Women were disproportionately burdened by family caregiving expectations resulting in stress and unwillingness to pass on this burden to their children. While there was sometimes a utopic dream about going back "home" during old age, there was also a strong, articulated desire to find a way to make U.S. caregiving systems available to older New London Hispanics. A shared view among participants was their willingness to remain independent and their aversion to institutionalization, nursing homes in particular, perceived as inhumane. Most participants also agreed that they lacked culturally adept information and support.

The majority acknowledged the biological and physical changes associated with chronological age. Perceptions of being old were positive reflecting the cultural context of the elder's importance to the group and the respect accorded for their contributions to the group as shown in the literature (Hilton et al. 2012). As one participant put it (we use 
italicized sentences when paraphrasing participants) ageing is not biological, but a state of the soul and of the mind, while another deemphasizing chronological age noted, someone in their forties can be old, while someone in their seventies might not. There was also a general consensus that ageing without a lack of integration within a social network is truly frightful. One participant noted: ageing is the gradual loss of certain faculties but you can go with dignity. It is important to count on resources and support [of your social network], because you cannot always count on good health. Isolation, as one respondent warned, affects older persons negatively; they must feel loved, they must be made to feel of use and valued. We should respect the concerns, ideas, and experiences of our aged.

Participants agreed that informal networks should assume the responsibility for ensuring that the individual's earned positions of respect and dignity remain as a person declines physically and mentally with age. It would seem that Latino families are closer to each other. When seniors are in our circle, they are not separated because they are part of the conversation. This obligation to older members of the community was repeatedly contrasted with what is perceived as a harsher, less respectful view of older persons in the U.S. As one participant noted, [Hispanic] children...sacrifice themselves [for the older member]. It does not matter to us to do it. The American culture is a very different thing from the Hispanic. Children raised in the United States with their Hispanic culture will not place their seniors in an institution. Here, they allow the aged to be institutionalized. I would never place my mother in a nursing home. This view is not supported by the 
available scholarship, which finds that the "vast majority" (about 87 per cent) of care for the aged in the U.S. is provided by informal, unpaid caregivers, usually family members (Brewer 2001). The differences in perceptions compared to reality may reflect an assumption of ideals over the realities associated with an inability to adequately care for an elderly parent.

One important finding was how gender affects ageing attitudes, expectations, and caregiving roles. Our male participants expected caregiving from women, usually daughters, while women—who disproportionately provided care—didn't necessarily assume this premise. While there was clear evidence that our Hispanic participants were aware of the need for planning, there seemed to be an unwritten understanding that most women would care for their elderly, making this "planning" somewhat unnecessary. Some male participants assumed that their children, primarily daughters, would provide informal long-term care to them. I told my children to not even dare think of placing me in a nursing home. Otherwise, I will end my life!, was passionately voiced by one participant. Another male participant said, I have five children and two are daughters. Since they love me, I know that they will take care of me. I mean my girls, not my boys, because they [boys] get easily distracted.

Women's perceptions about caregiving and receiving care differed from men's. Women who were caring for an ageing parent at the time or who had done so in the past, shared that it was "only natural" to do so. It's what we do in our [Hispanic] culture. My old man 
may die in my house, but not in a [nursing] home. But, they did not necessarily expect their children to take care of them and, in this sense, revealed some overprotectiveness towards their younger family members. Sentiments such as, Children are borrowed and have to live their own lives, were shared by more than one female participant across different focus groups. Another noted, I have children and I don't expect them to care for me. They can place me in a nursing home and, as long as they bathe me, I'll be alright. Other participants in the group nodded with approval.

Independence and autonomy were themes reflected in a number of responses focusing on the issue of burden. Several participating parents recognized the financial constraints faced by their children and actively avoided being an additional burden on them. One participant who worked in the social services field described how she came into contact with homeless people, some of whom were Hispanic seniors, who did not want to be a burden to their children. In many cases they preferred to get support from people who weren't family members. The desire to not be a burden extends beyond national boundaries, as detailed by one participant whose divorced parents live in Puerto Rico,...none of the children live in Puerto Rico and, to avoid placing a burden on her children, the mother is taking care of the father while the children contributed by purchasing life insurance for the father. If older parents were to live with their children, one said, there should be equality of responsibilities between parent and adult child. For example, the mother of a participant receives a pension of $\$ 800$ a month and pays her a "symbolic rent" because she does not want to live for free. Another participant was quite 
blunt in her unwillingness to give up her autonomy to live with adult children: there are people who want to live alone and independently rather than being cared for by a daughter-in-law!

Participants who had either worked in nursing homes or visited friends in these institutions described the elderly as abandoned, alone, and living in unsafe and prisonlike conditions. They lose their humanity and are treated without dignity, we heard participants lament; they fall asleep seated at their tables... and nobody helps them...They could die and no one would notice. Employees were not spared from the wrath of many in our groups: The treatment of the seniors by the employees leaves much to be desired... Employees sometimes are hypocritical and clean the seniors only when they are going to have an inspection. Employees are not friendly and mistreat the seniors. The anger and vitriol that characterized this discussion may reflect the fact that, contrary to the overall U.S. institutionalization rate which is declining, this rate is actually increasing for Hispanics because many families have found themselves with little choice but to institutionalize their elderly relatives (Fennell et al. 2011).

Gender also had an important role in planning decisions to permanently return to their countries of origin and regarding caregiving obligations when relatives are scattered across countries. Men had a more idyllic view of returning home and expressed a strong desire to go home to live "the good life," almost to the point of romanticizing their motherland. I will spend my last days in my country because it is less stressful and there 
is more solidarity, was a common quote among male participants. Another male participant shared, Life is comfortable in the U.S., but comfort comes at a high price. On the other hand, most women were not interested in returning "home" for multiple reasons, including an unstable and dangerous political or socio-economic climate in their countries of origin, the desire to adopt New London as their hometown, a reluctance to be separated from their children in the U.S., and the "older" role that they would play in their country's society. I felt older in my country when I was younger than I do now. Here, the elderly still work and have a sense of worth.

This gendered dynamic was played out during an exchange between a middle-aged husband and wife approaching retirement. The husband was the more vocal of the two and at one point explained why he planned to return to the Dominican Republic, I don't want to abandon my homeland for a country [U.S.] that isn't mine and having money isn't everything if you are going to die from stress here. In response, his wife, who had remained silent, visibly rolled her eyes and loudly proclaimed, This country has many great things: We have freedom and people respect the Law. This interaction is consistent with scholarship suggesting that women immigrants are much less likely to want to return to their country of origin because in the U.S., women may have considerably more autonomy and power in the household. In contrast, some Hispanic immigrant men, especially those who are unskilled labor migrants and who struggle with either low wage work or unemployment, long for the homeland where customs and gender expectations would allow them to reassert their power in the household (Pessar 1999). 
In addition to returning to their homeland as a long-term care planning option, participants also mentioned selecting a third country as a more affordable alternative (compared to New London) in terms of healthcare and housing costs. One participant who worked in a nursing home shared a story about a white U.S.-born co-worker who was about to retire. She summarized her co-worker's discovery...of residences for seniors in Mexico and Costa Rica in attractive settings that offer many services for the seniors. These services are a fraction of what they would cost in the United States. For that reason, I am thinking about retiring to a residence of Mexico or Costa Rica. Another participant expressed her financial frustration: It is very difficult to live and to save for retirement because one gains [earns] modestly; I will have to go to a place that is more comfortable (cheap) in my senior years; perhaps return to my country, half here and half there. I am not going to be able to afford living in New England. Several participants already had parents who lived a transnational life, spending time in both the U.S. and their homeland: The people who live here from another country need to return to see their relatives. Her mother comes from El Salvador although it has been 40 years since she arrived in the U.S. She travels frequently to El Salvador, has a pension and Social Security.

Participants were highly skeptical about Social Security pensions to cover the cost of their care as they aged. As one participant said, Social Security will not be able to cover the costs of the elderly, followed by another who warned, Social Security looks to protect the older persons but it doesn't, and pensions are insufficient. Many also voiced 
resentment against having to pay out-of-pocket costs after years of paying into Social Security and a pension plan, a system that will pay out so little despite years of making contributions. One participant who had worked in a factory for ten years indicated that what Social Security will give her will be insufficient. For that reason, she must look for other alternatives. Another argued that, Hispanic people work and pay their taxes, and then when you finally reach the age of retirement,... what happened to the money we paid all those years that we contributed to the system?

The costs of ageing, especially increasing medication costs and Medicare's inadequacy to cover the bills, were also discussed in fairly animated terms. One elder Puerto Rican woman noted problems with drug plans, It's the medication plan [referring to Medicare Part D] and it is the law that you have one... The "donut hole" (sighs abound in the room at hearing those words), that's when you have to start paying the bulk of the cost yourself. And, if you have a lot of medications, you hit that donut hole that much quicker. Problems with Medicare were also shared with considerable angst: You cannot find any doctor who will take you as a patient if you rely on Medicare. Also, Medicare does not cover all the costs, so when you tell the doctor you're on Medicare, they suddenly are no longer taking any new patients. It is ridiculous what Medicare covers - not much! (other participants in the group nodded in agreement).

Hence, while it is true that Hispanics may be less likely to engage in formal planning (preparing last wills and testaments or identifying legal health care proxies, for example), 
the basic tenor of our conversations suggested a clear awareness for the need to plan and the recognition of their responsibilities as parents and children to ensure that these needs were met. From our participants' narratives, planning within Hispanic families and communities is quite complex and reflects cultural imperatives, filial obligations, and difficult economic circumstances, which contrasts with available planning strategies for affluent social groups.

Late life and end-of-life decisions also seemed to be construed as a family responsibility. But many female participants emphasized that the parent should be the decision maker, not the child. This was consistent with the desire to not burden their children or other family members. One senior woman argued quite forcefully that people who are getting ready for their senior years are responsible for all the details of their end-of-life, including the burial (funeral expenses). She did not want her children to bear the burden of her burial. The same participant cautioned, without a last will and testament, the family is left to deal with the legal entanglements... which can be destructive. It is necessary to put in writing who inherits what. A general fear of death as an obstacle to end of life conversations was also mentioned several times. As one participant said, people get nervous and don't really want to talk about death...[They] believe they are going to live forever; that is why, in our countries, the life insurance business isn't successful. 
When discussing the actions of social service workers and agencies, participants typically shared experiences of encountering racism and inefficient access. One participant reported that when she requested assistance from an ageing center, she did not find support even among employees of the same ethnic group. Others shared experiences of indifference, incompetence, and inefficiency when working with state bureaucracies. A participant took her mother to the Office of Ageing to apply for financial help with her mother's medications. After they had filled out the paperwork and returned home, they never heard back or received any additional materials or notifications. We waited and waited, eventually returned to the office only to find that the forms had been lost. She filled out the forms again, and even after a year and a half nothing was approved. It's now been three years and my mother has yet to receive any help... This frustration has been documented in the literature (Delgadillo et al. 2004), and as one participant noted, ...most of the information is in English. You are required to fill forms to obtain aid; often those forms are lost, processed slowly, or have to be completed again.... It would be helpful if one could get assistance in their own language.

In sum, our participants expressed a significant awareness of the existing challenges to adequately prepare for their future. Their need "to fight" for their wellbeing was contrasted with a sense of distrust toward social services and health care bureaucracies. They emphasized a survival behavioral mode of "learning how to work the system." In other words, they recognized these institutions as hostile, but conquerable. Participants noted that the system could work for you, if you know how to play the game. Rather than 
giving up, the focus was on finding a way to get what you need. But our participants were also well aware of the complexities of understanding the operation of state bureaucracies and the need to raise concerns about older Hispanics who had recently immigrated and who did not speak English.

\section{Conclusions}

This research sought to understand how Hispanics interpret ageing and how they plan for it in a small coastal city in Connecticut, U.S. Our findings are largely consistent with the literature on ageing, bonding among Hispanics, and planning for old age. Culture and the influence of family norms affect ageing attitudes and long-term planning perceptions. Informal family caregiving arrangements and close circles of care in the community provide much needed support for older parents and relatives. However, these circles of care may be unsustainable and fragile due to the vulnerabilities of both older persons themselves and the social networks of family and friends. Balancing or integrating informal and formal systems of support in culturally respectful ways that provide dignity, security, and a sense of purpose to older Hispanics during their old age remains a work in progress.

Women carry a disproportionate responsibility in caregiving, which is often a source of stress. This situation may arise when caregivers in general, and female caregivers in particular, face challenges coming from obligations to care for the rest of the family, go to work, need to commute, take care of smaller children, adhere to limited budgets given 
low earnings, and navigate the intricacies of the formal health care system, including Medicare, to support the health of their ageing parents and relatives. Although formal caregiving in nursing homes is perceived as highly problematic, insensitive, and costly, when older persons are frail or severely ill, there is no other choice than to institutionalize the family member. Workshops for both female caregivers and older Hispanics may help both parties align their expectations about giving and receiving informal care at home. Older male Hispanics, in particular, would benefit from understanding that working daughters and a "sandwich generation" full of multigenerational caring responsibilities are realistic impediments to provide permanent care. Relaxing demands on female caregivers and extending the provision of care to the wider circle of family and friends can help alleviate stress, anxiety and depression from the elder and the expected caretaker(s).

Families and tightly knit communities are often ambivalent on which long-term care strategies to pursue, especially when facing language barriers, access to information, and high costs of formal caregiving and medications. With a few exceptions, social service agencies often lack multicultural competence to serve Hispanics and encounter difficulties in meeting their own institutional missions and goals. A process is needed to give Hispanics information on how to seek for support and to increase the availability and accessibility of formal and informal systems of care. Informed and effective planning will require continued dialogue and building partnerships among social service agencies to create more culturally sensitive and respectful interaction. 
Cultural and linguistic inadequacy of formal systems of care for older Hispanics and their families are important issues, too. All too often, information does not exist in Spanish, is fragmented or not comprehensive enough to serve the needs of this significant population. The way that information is presented is just as important. Simply offering detailed information in written form, even in Spanish, will not necessarily ease anxieties or enhance understanding of options available to older persons or the family. Dialogue and training to appropriately convey such information are key instruments to ensure that Hispanic families understand their options.

Planning for old age is very important among Hispanics in New London, but it is conducted in a different manner than in other sub-cultures from the U.S. There is less emphasis on saving for long-term care during the life span and addressing the issue of planning as a financial strategy. The problem regarding our Hispanic focus group participants is not that they do not plan or are not intentional in their planning. Rather, their present condition precludes them from establishing a sustainable informal care network. Unfortunately, state resources are both inadequate and ineffective in offering older Hispanics the opportunities to live independently or for their families to care for them.

A few utopian wishes or dreams emerged from this research regarding going back home in old age. This myth is based on the idea that life at home would be more welcoming 
and affordable. But even this option can be quite complicated to coordinate and may not always work. Long-term care planning is definitely a complex process that cannot be relayed to families only. We look forward to conducting future research which combines quantitative methods with qualitative approaches to provide additional policy recommendations.

\section{Statement of Ethical Approval}

The present research was reviewed and approved by Connecticut College's Institutional Review Board. It does not raise any ethical issues or concerns.

\section{Statement of Funding}

This research was partially funded by grants from Connecticut College's Research Matters program, the President's Fund for Student-Faculty Engagement, and the Center for the Comparative Study of Race and Ethnicity. One student who collaborated with this research was funded through the ConnSHARP summer research grant for student faculty collaborations.

\section{Statement of Conflict of Interest}

There is no conflict of interest that we are aware of. 


\section{References}

Angel, J. L., Angel, R. J. and Henderson, K. J. 1997. Contextualizing social support and health in old age: Reconsidering culture and gender. The International Journal of Sociology and Social Policy, 17, 9/10, 83-116.

Angel, J. L., Angel, R. J., Aranda, M. P. and Miles, T. P. 2004. Can the family still cope? Social support and health as determinants of nursing home use in the older Mexicanorigin population. Journal of Aging and Health, 16, 3, 338-54.

Angel, R. J., Angel, J. L., Lee, G. and Markides, K. S. 1999. Age at migration and family dependency among older Mexican immigrants: Recent evidence from the Mexican American EPESE. The Gerontologist, 39, 1, 59-65.

Angel, R. J., Frisco, M., Angel, J. L. and Chiriboga, D. A. 2003. Financial strain and health among elderly Mexican-origin individuals. Journal of Health and Social Behavior, 44, 4, 536-51.

Aranda, M. P., Ray, L. A., Snih, S. A., Ottenbacher, K. J.and Markides, K. S. 2011. The protective effect of neighborhood composition on increasing frailty among older Mexican Americans: A barrio advantage? Journal of Aging and Health, 23, 7, 1189-217.

Baker, S.S. 2002.Understanding Mainland Puerto Rican Poverty. Temple University Place, Philadelphia, PA. 
Bengtson, V. L. and Oyama P. 2010. Solidarity and Conflict. In M.A. Cruz-Saco and S. Zelenev (eds), Intergenerational Solidarity: Strengthening Economic and Social Ties. Palgrave Macmillan Press, New York, 53-80.

Bengtson, V. L., Lowenstein, A., Putney, N. M. and Gans, D. 2003. Global aging and the challenge to families. In V. L. Bengtson and A. Lowenstein (eds), Global Aging and Challenges to Families. Aldine de Gruyter, Hawthorne, New York, 1-24.

Bengtson, V. L., Giarrusso, J., Mabry, J. and Silverstein, M. 2002. Solidarity, conflict, and ambivalence: Complementary or competing perspectives on intergenerational relationships? Journal of Marriage and Family, 64, 3, 568-76.

Bengtson, V. L., Biblarz, T., Clarke, E., Giarrusso, R., Roberts, R. E. L., RichlinKlonsky, J. and Silverstein, M. (2000). Intergenerational relationship and aging: Families, cohorts, and social change. In J. M. Claire and R. M. Allman (eds), The Gerontological Prism: Developing interdisciplinary bridges. Baywood, Amityville, New York, 115-48.

Bengtson, V. L. and Mangen, D. J. 1988. Family intergenerational solidarity revisited. In D. J. Mangen, V. L. Bengtson and P. H. Landry (eds), Measurement of Intergenerational Relations. Sage, California, 222-38.

Bermúdez, J. M., Kirkpatrick, D., Hecker, L. and Torres-Robles, C. 2010. Describing Latinos families and their help-seeking attitudes: Challenging the family therapy literature. Contemporary Family Therapy: An International Journal, 32, 2, 155-72. 
Beyene, Y., Becker, G. and Mayen, N. 2002. Perception of ageing and sense of wellbeing among Latino elderly. Journal of Cross-Cultural Gerontology, 17, 2, 155-72.

Blackhall,L.J., Murphy,S.T., Frank, G.M., and Azan,V.S. 1995. Ethnicity and attitudes toward patient autonomy. Journal of the American Medical Association, 274, 10, 820-5.

Borrayo, E.A., Goldwaser, G., Vacha-Haase, T. and Hepburn, K.W. 2007. An inquiry into Latino caregivers' experience caring for older adults with Alzheimer's disease and related dementias. Journal of Applied Gerontology, 26, 5, 486-505.

Brewer, L. 2001. Gender socialization and the cultural construction of elder caregivers. Journal of Aging Studies, 15, 3, 217-35.

Burr, J. A. and Mutchler, J. E. 1999. Race and ethnic variation in norms of filial responsibility among older persons. Journal of Marriage and Family, 61, 3, 674-87.

Caralis, P. V., Davis, B., Wright, K. and Marcial, E. 1993. The influence of ethnicity and race on attitudes toward advance directives, life-prolonging treatments, and euthanasia. The Journal of Clinical Ethics, 4, 2, 155-65.

Carr, D. 2011. Racial differences in end-of-life planning: Why don't blacks and Latinos prepare for the inevitable? Omega, 63, 1, 1-20.

Debus, M. 1988. Handbook for Excellence in Focus Group Research. Academy for Educational Development. 
http://www.globalhealthcommunication.org/tool_docs/60/handbook_for_excellence_in f ocus_group_research_\%28full_text\%29.pdf (accessed in April 2015)

Dreby, J. 2009. Negotiating work and parenting over the life course: Mexican family dynamics in a bicultural context. In N. Foner (ed.), Across Generations: Immigrant Families in America. New York University Press, (pp. 190-218). New York, 190-218.

Delgadillo, L., Sorensen, S. and Coster, D. C. 2004. An exploratory study of preparation for future care among older Latinos in Utah. Journal of Family and Economic Issues, 25, $1,51-78$.

Edgell, P. and Docka, D. 2007. Beyond the nuclear family? Familism and gender ideology in diverse religious communities. Sociological Forum, 22, 1, 26-51.

Feng, Z., Fennell, M. L., Tyler, D. A., Clark M. and Mor, V. 2011. Growth of racial and ethnic minorities in U.S. nursing homes driven by demographics and possible disparities in options. Health Affairs, 30, 7, 1358-65.

Fennell, M. L., Feng, Z., Clark, M. A. and Mor, V. 2010. Elderly Hispanics more likely to reside in poor-quality nursing homes. Health Affairs, 29, 1, 65-73.

Foner, N. 2009. Introduction: Intergenerational relations in immigrant families. In N. Foner (ed.), Across Generations: Immigrant Families in America. New York University Press, New York, 1-20. 
Gassoumis, Z. A., Wilber, K. H., Baker, L. and Torres-Gil, F. 2010. Who are the Latino baby boomers? Demographic and economic characteristics of a hidden population. Journal of Aging and Social Policy, 22, 1, 53-68.

Gilbertson, G. (2009). Caregiving across generations: Aging, state assistance, and multigenerational ties among immigrants from the Dominican Republic. In N. Foner (ed.), Across Generations: Immigrant Families in America. New York University Press, New York, 135-59.

Gutheil, I. A. and Heyman, J. 2006. They don't want to hear us: Hispanic elders and adult children speak about end-of-life planning. Journal of Social Work in End-of-Life and Palliative Care, 2, 1, 55-70.

Herrera, A. P., Lee, J. W., Nanyonjo, R. D., Laufman, L. E. and Torres-Vigil, I. 2009. Religious coping and caregiver well-being in Mexican-American families. Aging Mental Health, 13,1, 84-91.

Heyman, J. and Gutheil, I. 2010. Older Latinos' attitudes toward and comfort with endof-life planning. Health \& Social Work, 35, 1, 17-26.

Hilton, J. M., Gonzalez, C. A., Saleh, M., Maitoza, R. and Anngela-Cole, L. 2012. Perceptions of successful aging among older Latinos in cross-cultural context. Journal of Cross Cultural Gerontology, 27, 3, 183-99.

Hollander, J. 2004. Social Context of Focus Groups. Journal of Contemporary Ethnography, 33, 5, 602-37. 
Kelley, A. S., Wenger, N. S. and Sarkissian, C. A. 2010. Opiniones: End-of-life care preferences and planning of older Latinos. Journal of the American Geriatrics Society, 58, 6, 1109-16.

Kirby, J. B. and Lau, D. T. 2010. Community and individual race/ethnicity and home health care use among elderly persons in the United States. Health Services Research, 45, 5, 1251-67.

Koenig, T. L. 2004. From a woman's viewpoint: Ethical dilemmas confronted by women of informal caregivers of frail elders. Families in Society, 85, 2, 236-42.

Liamputtong, P. 2011. Focus Group Methodology: Principle and Practice. Sage Publication, London.

Lowenstein, A. 2010. Determinants of the complex interchange among generations: Collaboration and conflict. In M.A. Cruz-Saco and S. Zelenev (eds), Intergenerational Solidarity: Strengthening Economic and Social Ties. Palgrave Macmillan Press, New York, 53-80.

Lowenstein, A. 2007. Solidarity-conflict and ambivalence: Testing two conceptual frameworks and their impact on quality of life for older family members. The Journal of Gerontology, Series B: Psychological Sciences and Social Sciences, 62, 2, S100-7.

Lowenstein, A. 2005. Global ageing and the challenges to families. In M. Johnson, V. L. Bengtson, P.G. Coleman \& T. Kirkwood (eds). Cambridge Handbook on Age and Ageing. Cambridge University Press, Cambridge, 403-13. 
Lowenstein, A. (2000). Intergenerational family relations and social support. German Journal of Geriatrics and Gerontology, 32, 202-10.

Menjivar, C. and Abrego, L. 2009. Parents and children across borders: Legal instability and intergenerational relations in Guatemalan and Salvadoran families. In N. Foner (ed.), Across Generations: Immigrant Families in America. New York University Press, New York, 160-89.

Mijoba, N. 2012. Interview with Nadesha Mijoba, President, Mijoba Communications on February 19, 2012.

Pessar, P. 1999. Engendering Migration Studies: The Case of New Immigrants in the United States. American Behavioral Scientist, 42, 4, 577-600.

Pew Research Center (2010). Census history: Counting Hispanics http://www.pewsocialtrends.org/2010/03/03/census-history-counting-hispanics-2/ (accessed in December 2015).

Radina, E., M. and Barber, C. E. 2004. Utilization of formal support services among Hispanic Americans caring for aging parents. Journal of Gerontological Social Work, $43,2 / 3,5-23$.

Ragin, C.C. and Amoroso, L. 2011). Constructing Social Research: The unity and diversity of method, $2^{\text {nd }}$ ed. Pine Forge Press, Thousand Oaks, CA..

Rodriguez, O. 2008. Connecticut State Data Center (CtSDC) Population Projections 2005 to 2030. Presentation to Connecticut Partnership for Balanced Growth. 
http://www.donaldpoland.com/documents_and_links/3-Don_Poland_Writings/CPBG_-

_State_Data_Center_Population_Projections.pdf (accessed in May 2015).

Ruiz, M. E. and Ransford, H. E. 2012. Latino elders reframing familismo: Implications for health and caregiving support., Journal of Cultural Diversity, 19,2, 50-7.

Ryvicker, M. 2011). Staff-resident interaction in the nursing home: An ethnographic study of socio-economic disparities and community contexts. Journal of Aging Studies, 25, 3, 295-304.

Scommegna, P. 2013 Exploring the Paradox of U.S. Hispanics' Longer Life Expectancy, Population Reference Bureau. http://www.prb.org/Publications/Articles/2013/ushispanics-life-expectancy.aspx (accessed in December 2014).

Tait, E. M., Laditka, S. B., Laditka, J. N., Nies, M. A. and Racine, E. F. 2011. Praying for health by older adults in the United States: Differences by ethnicity, gender, and income. Journal of Religion, Spirituality and Aging, 23, 4, 338-62.

Treas, J. 2009. Four myths about older adults in America's immigrant families. Generations, 32, 4, 40-5.

Treas, J. and Carreon, D. 2010. Diversity and our common future: Race, ethnicity, and the older American. Generations, 34, 3, 38-44.

Treas, J. and Mazumdar, S. 2002. Older people in America's immigrant families:

Dilemmas of dependence, integration and isolation. Journal of Aging Studies, 16, 243-58. 
Treas, J. and Batalova, J. 2007 Older immigrants. In K. Warner and P. Uhlenberg (eds)

Social Structures: The Impact of Demographic Changes on the Well-Being of Older

Persons. Springer, New York, 1-24.

United States Census Bureau. 2010. Older American population to become more diverse.

https://www.census.gov/newsroom/releases/archives/ageing_population/cb10-72.html.

(Accessed in April 2015)

Warren, C.A.B. and Karner, T. X. 2009. Discovering Qualitative Methods: Field

research, interviews, and analysis, 2nd edition. Oxford University Press, New York. 